\title{
Wetenskap op weg na 'n nuwe identiteit en samewerking
}

\author{
P.G.W. du Plessis \\ Departement Filosofie \\ Randse Afrikaanse Universiteit \\ JOHANNESBURG
}

\begin{abstract}
A traditional approach in (alvinist philosophy is to start with an analysis of cosmic diversity in order to find the identity of a particular phenomenon. and then to end with an account of the inter-relatedness between the phenomenon and other things. Although Stoker's philosophy tries to keep a balance between diversity and coherence as an entrée to reality - his later publications reflected a remarkable shift by emphasising the coherence and contextual meaning of things.

Taking the coherence and contextual meaning of things as the point of departure, this article explores a converse version of the traditional approach by using coherence (and not identity) as a means to sound out some new meanings of science and scientific co-operation.

An indication of transdisciplinary co-operation is rendered in terms of the preponderance of reality's call upon man 10 be known and cared for. The article ends with a few examples of unusual concepts that may serve as a revised index to identify w'orld-friendly and humane scientific activities.
\end{abstract}

\section{Inleiding}

$\mathrm{Na}$ aanleiding van Stoker se groter klem (in sommige latere publikasies) op kontekste en samehange, is daar sowat 'n dekade gelede 'n nuwe taak vir medestanders in die Christelike denktradisie geformuleer. Die taak het daarop neergekom dat vir 'n goeie begrip van die soewereiniteit of identiteit van 'n saak, dit juis nodig is om te weet binne watter relasies, kontekste en voorwaardes die betrokke saak bestaan en funksioneer (Du Plessis: 1983:1-3, 7). Die denktrant wat in die taakstelling verwoord word, wil ek verder beredeneer, veral omdat ek van die wetenskap liefs as 'n soort strategie en netwerk van kennis wil praat.

Eerstens gee ek 'n aantal gedagtes ter tipering van genoemde klem op samehange en kontekste by Stoker wat as 'n groeipunt vir verdere filosofiese denke ontwikkel 
kan word. Tweedens illustreer ek die betekenis van die klem op samehange/vervlegting/voorwaardes/kontekste deur te vra watter nuwe lig dit kan werp op die identiteit en betekenis van wetenskapsbeoefening en op vorme van wetenskaplike samewerking.

Ek wil nie beweer dat Stoker opsetlik bedoel het om in sy latere geskrifte en voordragte 'n sterk primaat aan vervlegting of universaliteit bo uniekheid of soewereiniteit te gee nie. Miskien moet 'n mens dit versigtiger stel en sê: Stoker se onopsetlike toenemende aandag aan samehange, perspektiewe, kontekste en sogenaamde hapantiese bepalings kan gesien word as ' $n$ groeipunt vir ' $n$ ander werkhipotese wat stel dat ons voortaan 'n insig in die geaardheid, struktuur, funksie en identiteit van dinge moet probeer verwerf deur veral en eerstens te vra na die betrokke samehange, voorwaardes en kontekste daarvan.

\section{Uniekheid (en verskeidenheid) of samehang (en inter- afhanklikheid) as primêre inset?}

Alhoewel dit tans nie die geleentheid is om dieper daarop in te gaan nie, is ek van mening dat Stoker tot ongeveer voor die verskyning van Beginsels en metodes in die wetenskap (1961) en van sy tweedelige Oorsprong en rigting in die sestigerbegin sewentigerjare 'n probleemstelling oorwegend so sou aanpak dat hy sou begin met ' $n$ analise van die tersaaklike verskeidenheid en dat hy sou eindig met 'n aanduiding van die eenheid, samehang en vervlegting. So byvoorbeeld stel hy in sy steeds lesenswaardige monografie Die grond van die sedelike op vernuftigdidaktiese wyse die vraag na die uniekheid of wesensgrond (van die sedelike) vóór die vraag na die samehang of afhanklikheidgrond (Stoker, 1941:21-64).

Daarmee bedoel ek dat hy vroeër metodies (metodologies) en ook kosmies (kosmologies) sou begin met die veelkleurige verskeidenheid in sy speurtog na die unieke aard van iets en daarna met die wonderlike samehang tussen onherleibare sake in die kosmos sou eindig (Stoker, 1933:30, 34, 53). Hierdie benadering van hom lê ook op een lyn met dit wat ons binne die Wysbegeerte der Wetsidee aantref: eers kom 'n uiteensetting van die beginsel van soewereiniteit in eie kring, waarna die beginsel van universaliteit in eie kring ter sprake kom (Dooyeweerd, 1935: deel 111: 3-300).

Maar in sommige van sy latere publikasies gebeur dit soms dat as Stoker probleme op sy de novo-manier aanpak, hy die essensie van 'n saak vanuit allerlei samehange, perspektiewe en kontekste aanbied. Anders as byvoorbeeld in Die grond van die sedelike begin Stoker dan met die relasies, die perspektiewe en kontekste. In die lig daarvan sal hy met onderskeidinge voortgaan om weer met interafhanklikheid en onderlinge verweefdheid te eindig soos byvoorbeeld in 
hoofstukke 12,13 en 14 van sy boek Beginsels en metodes in die wetenskap waar hy die vraag wat wetenskap is, behandel (Stoker: 1969a: 133 -147)

Dit is onder andere op grond van sy gevoeligheid vir relasies en kontekste dat Stoker afgekom het op die nuwe dissipline deontologie: die deontiese word nie by stof, plant, dier of God gevind nie, maar by die mens in sy verhoudings tot natuur, medemens en God (Stoker, 1967:37-38 en Stoker, (Jnr.) 1983:27-48).

In sy latere omwerking van die grondlyne van sy 'Wysbegeerte van die Skeppingsidee' sê hy dat die totaliteitsvraag dié grondvraag van die wysbegeerte is. In die proses kom hy ook na vore met die nuwe begrip van hapantiese bepaling as die omvattende bepaling van die kosmos as geheel (Stoker, 1970b:234 en 261 e.v.). Dit is ook hoe Stoker nuwe betekenisse van die 'primêre' taak van die staat ontdek het: hy vra na die kontekste, perspektiewe waarbinne die staat bestaan en funksioneer. Die begrip staat kry as't ware nuwe kontekstuele betekenismomente by (Stoker, 1970b:69-77).

Selfs sy vindingryke voorstel om die ideologies belaste term selfstandigheid of outonomie te vervang met eiestandigheid moet gesien word in die lig van sy klem op die interafhanklike samehang van die betrokke saak met ander sake; vandaar dat hy dit (selfstandigheid of outonomie) 'n kreatuurlike onselfstandige eiestandigheid noem (o.a. Stoker, 1970a:204 e.v; 316 e.v.).

Stoker se 'Wysbegeerte van die Skeppingsidee' is ook 'n opsetlike poging om dualismes te oorwin deur onderlinge samehange en interaksies bloot te lê. Hy wil nie spannings tussen wetenskap en geloof, tussen godsdiens en kultuur, tussen eenheid en differensiasie, tussen mens en wêreld ophef deur genoemde pole van mekaar te skei nie. Nee, sy filosofie kom met voorstelle om die dualismes te oorwin deurdat hy byvoorbeeld vra hoe die pole mekaar wedersyds komplementeer en van mekaar afhanklik is (Stoker, 1967:347).

Oorsprong en rigting is ook die veelseggende titel van Stoker se tweedelige werk. Die ganse kosmiese werklikheid is vir Stoker 'n totaliteit met 'n samehangende verskeidenheid. Deur sy klem op die sub specie aeternitatis-perspektief ontdek hy die ryke verskeidenheid én die kreatuurlike sameliang. Dan is die skepping 'n "wonder-like onderlinge verbondenheid van sy radikale verskeidenheid" (Stoker, 1967:12). (My kursivering - PGWdP.)

Met my kursivering van die woord "verbondenheid" by Stoker wil ek beklemtoon dat die wonderstruktuur van die skepping nie (soos menige Cliristendenker wel beweer) slegs of hoofsaaklik in die verskeidenheid self lê nie, maar dat die wonderstruktuur skerp na vore kom in die ondersoek na samehange, vervlegtings en kompleksiteite van die verskeidenheid. Daarmee probeer ek ook om Stoker se 
balans tussen "verskeidenheid" (uniekheid) en "samehang" (interafhanklikheid) in die guns van laasgenoemde te swaai.

As aanvulling en soms as wysiging van sy siening wil ek daarom die volgende vermoede of werkhipotese verder toelig: dat dit (metodologies en inhoudelik) die moeite werd is om ' $n$ saak of probleem primêr vanuit die betrokke samehange en kontekste te benader, in plaas daarvan om dit primêr vanuit die vraag na die eieaard of uniekheid of identiteit daarvan te bekyk. Hierdie werkhipotese wil ek kortliks gebruik in 'n duiding van nuwe vorme van wetenskaplike samewerking as ons die wetenskap primêr vanuit sy samehange en kontekste sou benader.

\section{Transdissiplinêre samewerking}

Die vraag wat wetenskap is, word dikwels beantwoord deur primêr te let op die unieke kenmerke waardeur dit van ander sake verskil. Dink maar aan die oorbekende onderskeid tussen wetenskaplike en voor-wetenskaplike kennis binne die kring van Calvinistiese filosofiese denke (o.a. Dooyeweerd, 1935; Strauss, 1969; Van Riessen, 1970).

Sodra die vraag wat wetenskap is, hoofsaaklik beantwoord word in die lig van unieke en dus onderskeidende kenmerke soos byvoorbeeld die betrokke eiesoortige studieveld en die gepaardgaande sistematiese ordening en bewerking van gegewens, dan is daar weinig sprake van 'n kreatiewe gesprek tussen verskillende wetenskappe. Samewerking tussen wetenskappe beteken dan dat die onderskeie wetenskappe onafhanklik van mekaar hulle studieverslae oor fassette van die werklikheid of oor verskeie fasette van 'n gemeenskaplike probleem voorlê. Selfs die beplanning en uitvoering van navorsing vind los van mekaar plaas, veral omdat elke vak sy eie studieveld of probleemarea moet ontgin. Daar is ook geen finale sintese van bevindings nie.

Samewerking tussen wetenskappe neem in hierdie opsig die vorn aan van 'n multi-dissiplinêre benadering. Samewerking is hoofsaaklik beperk tot 'n administratief-organisatoriese gesprek oor wie doen wat, en wanneer lewer elkeen sy verslag in. Die omvattende verslag lyk soos 'n laslappieskombers, omdat dié soort samewerking hoogstens daartoe in staat is om 'n omnibusverslag voor te lê.

Soms word verskille tussen wetenskappe liefs na aanleiding van spesifieke tegnieke, vaardighede, die eie sisteem en hipoteses, eie metodes van probleemstelling en van probleemoplossings verduidelik. Selfs 'empirie' en 'begronding' in die fisika is iets anders as empirie en begronding in die kunsgeskiedenis of in taalwetenskap. Daar kan dus wel oorvleueling tussen die studievelde van wetenskappe wees, maar die metodes van kennis insamel en van toetsing verskil nogal aanmerklik. 
Wat hierdie aspek betref, word vooraf by die beplanning van samewerking tussen verskillende dissiplines eerstens gelet op die veelkantigheid van die gemeenskaplike probleemgebied wat tweedens met behulp van verskillende navorsingsmetodes ontgin moet word. Daar word dus gehoop om agterna 'n geheelbeeld te verkry deur gesamentlik na die afgehandelde navorsing te kyk en te vra hoe die bevindings by mekaar aansluit, mekaar komplementeer. Sodoende staan wetenskap in diens van 'n dissiplinêre instrumentarium, ' $n$ metodiese tug, 'n dissiplinêre metode. Samewerking tussen wetenskappe is eerder 'n samewerking tussen dissiplinêre metodes. Samewerking verkry in hierdie opsig 'n interdissiplinêre karakter.

Maar seifs die interdissiplinêre samewerking is 'n soort resultaat of gevolg van afsonderlike dissiplines en studiemetodes, want interdissiplinêre samewerking is ingestel op die verkryging van samehange en 'n integrale geheelbeeld as resultaat van die komplementariteit van metodes. Wetenskap ontstaan egter nie slegs deurdat die navorser met behulp van 'n spesifieke metode hom op 'n eiesoortige probleemgebied toespits nie. Wetenskap ontstaan as ' $n$ program van aktiwiteite binne verskeie kontekste. So is wetenskap ook verantwoordbare kennis wat op talle maniere getoets en begrond moet word. Wetenskap as strategie (moet) let op sy voorwaardes, grense, belange en verantwoordelikhede.

Ek sou verkies om die wetenskap as 'n strategie van kennis en kennisbelange te sien. Wanneer wetenskap as 'n strategie benader word, word gevra na die pertinente samehange tussen die wetenskap as 'n eiesoortige vraagstelling (en gepaardgaande metodiese dissipline) oor 'n nog onafgeronde probleemgebied, enersyds met sy kompleks van voorwaardes, oogmerke en andersyds sy verantwoordelikhede (Du Plessis, 1979:282).

Die strategie van die wetenskap dui veral op twee sake: Eerstens dui dit op omvattende kontekste, op allerlei relasies en beperkings en voorwaardes van wetenskaplike kennisvorming. Ons sou dit ook die hermeneutiese omgewing (veral kultuur, beskawing, politiek, sosio-ekonomiese ontwikkeling, moraliteit, religieuse instelling) kon noem waarbinne enige wetenskap met sy spesifieke studieveld en dissiplinêre ordening of metodes moontlik gemaak word. Die vraag wat wetenskap is, kom byvoorbeeld nie op binne 'n boendoe-samelewing nie: so 'n vraag ontstaan binne die konteks van kultuurhistoriese ontwikkelings waar daar onder andere sprake is van 'n universiteit as die werkswinkel van die wetenskappe. Binne ons kultuurhistoriese opset vorm wetenskap 'n (te groot?) deel van ons hedendaagse kultuurgoedere; daarom kom die bekende vraag na vore of wetenskap ook produk van ons kultuur is naas die omstandigheid dat kultuur as wenslike produk van ons wetenskap voorgestel word. 
Tweedens dui die strategie van die wetenskap veral op die verantwoording, toetsing en begronding wat die wetenskaplike saam met ander wetenskaplikes (en ander belangegroepe) van genoemde kontekste en voorwaardes doen en moet doen. Dergelike toetsing, begronding en verantwoording is nie ekstra- of buitewetenskaplike aktiwiteite nie. Toetsing, begronding en verantwoording is (moet) 'n inherent strategiese kenmerk van wetenskaplike optrede (wees); daarom kan hierdie kennis as betreklike kennis aangebied word - nie as onfeilbare suiwer wetenskap nie. Onderlinge verantwoording leer ons gou dat wetenskaplike sekerheid geen absolute sekerheid is nie en dat beskeidenheid ' $n$ deug in ons wetenskaplike ondernemings kan wees.

Gesonder groei en toename van ons vakkennis gaan onherroeplik gepaard met 'n besef dat nuwe kennis ook nuwe onkunde en nuwe onsekerhede skep en daarom weer nuwe aksieplanne (of strategieë) van ons verg. Vanuit ons benadering van wetenskap as strategie moet ons die onvoltooidheid van die wetenskap aanvaar; na elke nuwe verklaring erken en ontdek ons gou weer nuwe raaisels. Wie het die onfeilbare resep teen wetenskaplike dwaling en inkompetensie?

Ons kan die fuga as metafoor gebruik om die kompleksiteit en simfoniekarakter van wetenskap te verduidelik. Wetenskap is 'n meerstemmige onderneming waarin die navorsers probeer saamstaan en saamstem; dit is geen enkelvoudige of eenduidige saak nie. Wetenskap is geen statiese saak nie; dit kom tot stand vanuit 'n kompleks van voorwaardes, oogmerke, relasies, en van verantwoordelikhede.

Dit beteken onder andere dat wetenskap nie buite mededeling aan en kommunikasie met kollegas, studente, die beroepswêreld, politici en belangegroepe in die res van die samelewing beoefen kan word nie. Wanneer ' $n$ nie-filosoof (byvoorbeeld 'n regswetenskaplike of 'n fisikus of 'n taalwetenskaplike) uitsprake lewer oor nie-filosofiese aangeleenthede, sien ons dit nie onmiddellik as 'n onwetenskaplike inmenging in die filosofiese debat nie. Dan besef ons dat die werklikheid ingewikkelder is as enige wetenskapsindeling. Al is ons wetenskaplike metodes en ons logika van begrippe en ons kognitiewe sisteem iets unieks aan ons vakkennis, dit word gerelativeer, verryk en selfs gewysig deur onder andere ons menslike waardes en die komplekse werklikheid self.

Wetenskaplike kennis ontwikkel dus nie net na aanleiding van 'n sogenaamde immanent-teoretiese dinamiek nie; dit groei juis omdat die werklikheid self 'n aanstoot vir ons denke word. Transdissiplinêre samewerking is ' $n$ vorm van interdissiplinariteit wat 'n konstruktief-kritiese houding openbaar en wat pertinent aandag gee aan gemeenskaplike kontekste van wetenskappe (Du Plessis, 1979: 285). Transdissiplinêre wetenskapsbeoefening kweek by ons 'n nuwe wetenskaplike gevoeligheid en speursin vir grense, voorwaardes en kontekste van alle wetenskaplike kennis. 
Waar ons oor ons vakgrense heell saam kyk na vraagstukke wat aan ons vakke gemeenskaplik is en waar ons onsself laat verryk deur die insig van ander vakke oor ons probleemstelling, daar verkry ons wetenskaplike kennis en insig oor ons eie vakgrense heen; daar beoefen ons wetenskap op 'n transdissiplinêre wyse.

Dit wil voorkom asof Stoker se begrip intermediêre wetenskappe 'n vorm van transdissiplinêre samewerking kan aandui. Hy ontdek dié soort wetenskappe deur te let op gemeenskaplike seksies tussen wetenskappe. Hy verduidelik intermediêre wetenskappe met die gemeenskaplike seksie tussen twee sirkels wat mekaar sny; die gemeenskaplike gebied kan van die een of die ander kant benader word; alhoewel fisika en chemie onderskeie wetenskappe is, sny hulle mekaar ook. Die gemeenskaplike seksie, chemiese fisika of fisiese chemie, is intermediêre wetenskappe (Stoker, 1972?:34-35).

Iemand wat wetenskap beoefen as strategie van betreklike kennis wat voortdurend gewysig kan word en rekenskap gee van die metodes, doelstellings, die teoretiese en voorteoretiese raamwerke of paradigmata waarbinne by wetenskap beoefen, dra konstruktief by tot ' $n$ nuwe identiteit van die wetenskap. Daar waar die vakman bereid is om sy eie vakkennis te relativeer en in kontekste te laat beoordeel, daar waar die een wetenskaplike hom oopstel vir kritiek en verryking deur ander vakkundiges wat met ander raamwerke werk - daar word wetenskap op transdissiplinêre wyse beoefen. Hierdie werkwyse bied volop geleentheid om tradisionele vakgrense en vakkennis te oorskry, aan te vul en te wysig.

\section{Wetenskap met 'n nuwe identiteit?}

Stoker se gedagte dat die radikale kosmiese verskeidenheid ons op 'n legio wyses van samehang laat stuit, sou ons dus anders wou uitbou met 'n konvers-benadering: dat die kosmiese verskeidenheid duideliker word en soms eers ontdek word in die lig van allerlei onderlinge netwerke en betrokkenheid op mekaar. Insig in die samehange en onderlinge afhanklikheid bring ook nuwe insig in die identiteit van 'n saak.

Nog sterker gestel: kom ons waag dit om eers duidelikheid te soek oor die samehange voordat ons die vraag na die identiteit/uniekheid/eie-aard van 'n saak stel. Vertaal in klassiek-Calvinistiese terne: kom ons gebruik die beginsel van universaliteit in eie kring as toegang tot die werklikheid - en nie die beginsel van soewereiniteit in eie kring nie! Ons behandeling van wetenskap as strategie is ' $n$ poging om hiervan 'n illustrasie gee. Wanneer die samehange geïgnoreer of afgeskeep word, word ' $n$ bepaalde saak reduksionisties en/of parsieel en/of absolutisties beskou. Ons wetenskap is eers dan wetenskap as dit 'n verantwoordelike wete het (en dit deurlopend verwerf) van die onderlinge afhanklikheid tussen wetenskap en nie-wetenskaplike sake soos onder andere kultuur en morele 
waardes asook tussen wetenskap en wetenskap. Ons wetenskap is eers dan wetenskap as dit ook geskep en verryk word deur sogenaamde buite-, voor-, na- en ander wetenskaplike insigte, faktore, gronde, waardes, ensovoorts.

Met 'n dergelike wete kan die wetenskap vir die samelewing tot 'n seën wees deur 'n nuwe of gewysigde identiteit te ontwikkel; ' $n$ nuwe identiteit waarin wetenskap nie vereenselwig word met ' $n$ bedreiging van ons vryheid en verantwoordelikheid nie of met besoedeling van ons omgewing nie of met ondermyning van ons sosiale gewete of met tegniese vaardighede en gerief nie (Schuurman, 1993:26 e.v.).

Wetenskap en tegnologie vorm vandag nog die imperium van die rasionele denke. In hierdie imperium wat veral deur doel-rasionaliteit gekenmerk word, is weinig plek vir estetiese of etiese of juridiese of religieuse of emosioneel-affektiewe sake. Spontaneïteit word verdring deur berekenbaarheid. Betroubaarheid word bedreig deur effektiewe funksionaliteit. Gekonstrueerde beleid verdring intuitiewe wysheid of kreatiwiteit. Redelikheid maak geloof verleë. Die vraag hoe ons samelewing rasioneel en wetenskaplik beheersbaar is, versmoor die vraag of dit wenslik is om die samelewing rasioneel/wetenskaplik te beheers.

Die vraag hoe ons samelewing rasioneel beheer kan word, is gewoonlik afgestem op hoe dit effektief, gerieflik en funksioneel gedoen kan word. Die vraag of dit wenslik is om ons samelewing rasioneel te beheer, wil egter rekening hou met allerlei (morele, sosio-kulturele, ekonomiese e.a.) verhoudings en voorwaardes waarbinne 'n gangbare rasionele beheersing gerelativeer word. Sodoende word die weg vrygemaak om rasionele beheersing op sy beurt te beheers, maar dan eerder met nie-rasionele kragte soos morele trou, estetiese verwondering, ekonomiese sorg en juridiese billikheid. Genoemde vrae is op hulle beurt juis nie wetenskaplik-tegnologies op te los nie, ook omdat die mens en sy waardes en sy kultuur nie volledig onderdeel van natuurgebeure of tegnologiese prosesse is nie Daarom behoort wetenskap en tegniek nie ons verantwoordelikheid en ons keuses weg te neem of - soos dikwels gebeur - in te ruil vir tegnologiese gemak nie.

Met bovermelde teenstelling suggereer ek dat wetenskaplike kennis nie eerstens gelyk moet wees aan die uitbreiding van rasionele beheersing en funksionaliteit nie. Saam met Schuurman kan ons sê: "Het benadrukken dat wetenschappelijke kennis bepaald, betrekkelijk en beperkt is, is nu meer dan ooit nodig" (Schuurman, 1977:29). Wetenskaplike kennis behoort eerder die uitbreiding van ons verantwoordelike bewuswees van allerlei tersaaklike relasies waarbinne die mens self en waarbinne sy studievoorwerp optree, te impliseer. Ons uitbreiding van kennis van sake moet primêr gepaard gaan met die verrekening van allerlei samehange, verbande, belange en kontekste. Insig in die samehange en betreklike kondisies gee nuwe insig in die betekenis en identiteit van 'n saak. Dan sien ons nie meer manipuleerbaarheid, verifikasie, logiese deursigtigheid, beheersing, vereenvoudiging, voorspelling en grootskaligheid as prohleemlose trefwoorde wat 
die wetenskap moet identifiseer nie. Wanneer ons met ons wetenskaplike kennis streef na 'n grenslose wetenskaplik-tegniese beheersing en kontrole oor natuur, mens en samelewing, word wetenskap op ' $n$ onverantwoordelike wyse beoefen (Schuurman, 1993:11 e.v.). Dan kyk ons die grense, voorwaardes en relasies waarbinne wetenskap funksioneer en moontlik is, ook mis. Dan streef ons slegs na een stel waardes, naamlik na helderheid, eenvoud, stabiliteit, kontrole, vaardigheid, eksklusiwiteit, orde en manipuleerbaarheid. Dié eksperiment van die sogenaamde moderne wetenskap met sy groot ideale om rasionaliteit en vooruitgang op alle lewensterreine uit te brei, het egter gelei tot ' $n$ massale devaluasie van menslike vryheid en waardigheid (vergelyk o.a. Müller-Schwefe, 1965; Roszak, 1968; Toffler, 1984).

Deur egter te let op netwerke, kontekste, samehange en onderlinge aflanklikheid tussen wetenskap en sy omgewing, kan ons genoemde eensydige stel waardes deurbreek. Dan kom mens onder die indruk dat betrekkinge, kontekste en afhanklikheid aan ons 'n identiteit gee; dan stuur ons weg van die wêreldbeeld dat alles nnakbaar is. Teenoor 'n Faustiese hoogmoed van die moderne waan dat die mens homself en sy wêreld self kan maak, kan ons wys op die paradoksale situasie dat ons die identiteit van die wetenskap (en mens en wêreld) ontdek vanuit iets anders. Identiteit word ons aangebied deur verhoudinge, funksies, die tradisie, die transendente.

Identiteit word die wetenskap en die wetenskaplike geskenk vanuit 'n netwerk en ingeskakeldheid met die res van die werklikheid. Ook hier dui 'netwerk' en 'ingeskakeldheid' op die relatiwiteit en heenwysende karakter van dinge. 'n Tipiese kenmerk van wetenskap, mens en wêreld is juis die ontvanklikheid vir iets anders, 'n nie-afgeslotenheid of religieuse uitreiking bo hulself, want die kenbare dinge vra en roep om geken te word (vgl. Stoker, 1969a:293-297; Stoker, 1969b: 242-247). Wetenskap ontstaan nie primêr deur ' $n$ immanente inisiatief van die mens nie. Wetenskap en kennis is ' $n$ antwoord van die mens op die oop vraag van die kenbare, die roep om geken en versorg te word. Die vraag is eerste en gaan aan die antwoord vooraf; sodoende word wetenskaplike aktiwiteite moontlik deur voorafgegewenes of antesendente of geskenke.

Waar Stoker praat van die teale bepaaldheid van die kosmos (“... alles wat tot ons skepping behoort, wys kragtens sy kreatuurlikheid, onselfgenoegsaamheid en wetsonderworpenheid heen na sy Oorsprong ..." - Stoker, 1970a:415-416 en Stoker, 1971) sou mens in meer humanistiese taal kon stel: die mens en sy wetenskap is geen causa sui nie. Sodoende word wetenskap 'n ontmoetingspunt met God, 'n ruimte of aktiwiteit waar God en sy openbaring van die begin af aanwesig is en ontdck kan word. Hiermee kom ons af op alternatiewe én bykomende waardes en kenmerke soos belange, gawe en oorgawe, genade, geloof. (grond)motief, die kontingente, openharing. vermoede, vertroue, wonderstruk- 
ture, dinamiese weerbarstigheid, spanning. komplekse samehange, netwerke en kontekste waarmee goeie wetenskapsbeoefening voortaan geïdentifiseer kan word.

\section{Literatuur}

DOOYEWEERD, H. 1935. Wijsbegeerte der Wetsidee, deel III. Amsterdam : Paris.

DU PLESSIS, P.G.W. 1979. Moderne tendense in die wetenskapsbeskouing. Tydskrif vir Geesteswetenskappe, 19(4):273-285

DU PLESSIS, P.G.W. 1983. 'n Opdrag en vinding in Stoker se wetenskapsleer. Potchefstroomse Studies in Christelike wetenskap, Potchefstroom : PU vir CHO

MüLLER-SCHWEFE, H. 1970. Technik und Glaube. Göttingen : Vandenhoeck.

ROSZAK, Th. 1968. The Making of a Counter Culture. New York : Faber.

SCHUURMAN, E. 1977. Techniek: middel of moloch? Kampen : Kok.

SCHUURMAN, E. (e.a.) 1993. Reformatoriese cultuurvisie. Nunspeet : Marnix van Sint Aldegonde Stichting.

STOKER, H.G. 1933. Die Wysbegeerte van die Skeppingsidee. Pretoria : De Bussy

STOKER, H.G. 1941. Die grond van die sedelike. Stellenbosch : Pro Ecclesia.

STOKER, H.G 1967. Oorsprong en rigting, deel 1. Kaapstad : Tafelberg.

STOKER, H.G. 1969a. (Tweede onveranderde druk): Beginsels en metodes in die wetenskap. Johannesburg: De Jong.

STOKER, H.G. 1969b. "Christelike wetenskap; 'n noodwendigheid". Die atoomeeu in U lig. Potchefstroom : IBG. p. 239-253.)

STOKER, H.G. 1970a. Oorsprong en rigting, deel 2. Tafelberg : Kaapstad.

STOKER, H.G. 1970b. Die aard en rol van die reg. RAU-publikasiereeks, Johannesburg : RAU.

STOKER, H.G. 1971. The Theory of Knowledge of prof. dr. C. Van Til. (In Geehan E.R. ed. Jerusalem and Athens. Van Til-Festschrift. New Jersey : Presbyterian \& Reformed Publishing Company. p. 25-71.)

STOKER, H.G. 1972(?). Christelike opvoedkunde en sy plek in die sisteem van 'n Christelike wetenskap. Studiestuk nr. 8. Potchefstroom: Christelike Opvoedkundevereniging van Suid-Afrika.

STOKER, H.G. (Jnr.) 1983. Die vraagstuk van die deontologie in die filosofie van H.G. Stoker. Potchefstroom : PU vir CHO. (MA-verhandeling.)

STRAUSS, D.F.M. 1969. Wysbegeerte en vakwetenskap. Bloemfontein : Sacum.

TOFFLER, A. 1984. Future Shock. Bantam Books : New York.

VAN RIESSEN, H. 1970. Wijsbegeerte. Kampen : Kok. 